\title{
Recent improvement in long-term survival after a COPD hospitalisation
}

\author{
Pere Almagro, ${ }^{1}$ M Salvadó, ${ }^{1}$ C Garcia-Vidal, ${ }^{1}$ M Rodriguez-Carballeira, ${ }^{1}$ M Delgado, ${ }^{1}$ \\ B Barreiro, ${ }^{2} \mathrm{~J}$ L Heredia, ${ }^{2}$ Joan B Soriano ${ }^{3}$
}

- Supplementary figures/ tables/appendix are published online only at http://thorax.bmj. com/content/vol65/issue4

${ }^{1}$ Internal Medicine Services, University Hospital Mutua de Terrassa, Terrassa, Spain ${ }^{2}$ Respiratory Services, University Hospital Mutua de Terrassa, Terrassa, Spain

${ }^{3}$ Program of Epidemiology and Clinical Research, Fundación Caubet-Cimera Illes Balears, International Center for Advanced Respiratory Medicine, Bunyola, Spain

\section{Correspondence to}

Dr Pere Almagro, Internal Medicine, Hospital Mútua de Terrassa, Pza. Dr. Robert no. 5, Terrassa 08221, Barcelona, Spain; 19908pam@comb.cat

Received 3 August 2009 Accepted 16 November 2009

\begin{abstract}
Background Evidence-based international guidelines on chronic obstructive pulmonary disease (COPD), and their corresponding recommendations, were established to improve individual COPD prognosis, and ultimately to improve survival. The aim of this study was to determine whether the long-term mortality after discharge from a COPD hospitalisation has improved recently, and the effect of co-morbidity treatment in improving COPD prognosis.
\end{abstract}

Methods In a prospective cohort study design of two cohorts 7 years apart, patients discharged from the same university hospital after a COPD exacerbation were followed-up, and their outcomes compared.

Demographic and clinical variables, as well as lung function, were collected with the same protocol by the same investigators. Comprehensive assessments of comorbidities and treatments were undertaken.

Kaplan-Meier survival curves were estimated, and outcomes were compared by means of Cox regression methods.

Results Overall, 135 participants in the 1996-7 cohort and 181 participants in the 2003-4 cohort were studied. Both cohorts were comparable in their baseline demographic and clinical variables, and median follow-up was 439 days. The 3-year mortality was lower in the 2003-4 cohort (38.7\%) than in the 1996-7 cohort $(47.4 \%)(p=0.017)$, and the RR of death after adjustment for gender, age, body mass index, comorbidities, lung function and mMRC (modified Medical Research Council scale) dyspnoea was 0.66 (95\% Cl 0.45 to 0.97$)$. Long-term survival improved in the second cohort for patients with COPD with heart failure or cancer $(p<0.001)$.

Conclusions $A$ recent trend towards better prognosis of patients with COPD after hospital discharge is described and is likely to be associated with better management and treatment of COPD and co-morbidities.

\section{INTRODUCTION}

Chronic obstructive pulmonary disease (COPD) is widely recognised as a major, and growing, cause of mortality and morbidity worldwide. ${ }^{1}$ Currently COPD accounts for $4.8 \%$ of global deaths, and the WHO predicts its mortality burden will increase to $7.9 \%$ by $2030 .^{2}$ Regarding prevalence, at least 1 in 10 adults is identified with COPD in population surveys. $^{3}$

COPD is currently considered a preventable and treatable disease, in which co-morbidities play a significant role. ${ }^{4}$ Cardiovascular disease, cancer and other non-respiratory-related diseases occur throughout all severity stages of COPD, and their impact can have significant implications in the long-term prognosis of patients with COPD. ${ }^{5}$

Until recently only smoking cessation and longterm oxygen therapy in patients with hypoxia were considered as improving survival in patients with COPD. However, new evidence from trials and meta-analyses has emerged suggesting that several respiratory drugs may have an impact on mortality. $^{6-10}$ It is not known whether these changes modify the overall prognosis after a COPD hospitalisation. COPD admissions usually occur in patients with severe disease, frequent co-morbidities and a poor prognosis. ${ }^{11} 12$ Clinical insight signalled that a better, holistic management of the patient with COPD and conditions associated with the illness might be related to better individual outcomes, although to the best of our knowledge to date there are no published studies exploring this hypothesis.

The aim of this research was to determine whether the long-term mortality after discharge from a COPD hospitalisation has been reduced recently, and to learn about the effect of co-morbidity treatment in improving COPD prognosis.

\section{METHODS}

This is a prospective cohort study design, following-up patients discharged from hospital after a COPD exacerbation that required a hospitalisation. The two cohorts of patients were 7 years apart, 1996-2003. All patients were admitted to and discharged from the Hospital Mútua de Terrassa, a 450-bed university hospital in the city of Terrassa, close to Barcelona, Spain.

\section{Inclusion and exclusion criteria}

Inclusion and exclusion criteria were the same for both cohorts. Briefly, all consecutive patients admitted for an acute exacerbation of COPD to any medical ward at our institution during the periods October 1996 to May 1997 and June 2003 to September 2004 were studied. Inclusion criteria were: (1) hospitalisation for suspected COPD exacerbation at admission and confirmed at discharge; and (2) forced spirometry showing postbronchodilator forced expiratory volume in $1 \mathrm{~s}$ $\left(\mathrm{FEV}_{1}\right) /$ forced vital capacity $(\mathrm{FVC})<0.7$ and an $\mathrm{FEV}_{1} \leq 70 \%$ of their reference value, compatible with COPD of at least moderate severity.

The timing of forced spirometry was different for the two cohorts, this being the only protocol change between them. Spirometry was conducted on discharge in the 1996-7 cohort, while it was conducted 1 month after discharge in the 2003-4 cohort. To avoid any potential survival bias due to 
our protocol change in the timing of spirometry, those patients in the 2003-4 cohort who died between discharge and the scheduled outpatient follow-up visit 1 month later were still included, and lung function data within the previous 6 months were used.

Exclusion criteria were a history of asthma, pneumonia or pulmonary oedema at admission, hospitalisation for causes other than a COPD exacerbation, bronchiectasias as predominant disease, death during hospitalisation or patient refusal to participate in the study. In all cases, the need for hospitalisation was decided upon by the doctors on duty in the Emergency room. The study protocol was approved by the Hospital Research and Ethics Committee, and all subjects gave their written informed consent.

\section{Measurements}

Lung function was assessed in the lung function laboratory by means of forced spirometry prebronchodilator test and postbronchodilator test, and reviewed by a chest physician. Spirometry was conducted according to the Spanish SEPAR guidelines, which mirror the American Thoracic Society (ATS)/European Respiratory Society (ERS) guidelines, and severity staging was assessed according to international guidelines. ${ }^{41314}$ Measurement of arterial blood gases (partial pressure of oxygen and carbon dioxide; $\mathrm{PaO}_{2}$ and $\mathrm{PaCO}_{2}$ ) at rest was made during room air breathing, and the body mass index (BMI) was calculated. Data on the presence of cor pulmonale, use of chronic oxygen therapy, number of admissions for COPD in the previous year and smoking history, as well as all demographic and clinical information, were collected upon admission. On discharge, arterial blood gas measurement was repeated. As detailed elsewhere, ${ }^{11}$ the following information was collected and questionnaires were completed the day before hospital discharge: (1) number and names of drugs and doses per day taken by the patient at home prior to admission; (2) dyspnoea as assessed with the modified Medical Research Council (mMRC) scale; (3) co-morbidities using the Charlson index ${ }^{15}$; (4) functional dependence at 2 weeks prior to admission with the Katz Activities of Daily Living Scale ${ }^{16}$; (5) residential status, as living alone, with relatives or institutionalised; (6) marital status, as currently married or unmarried (including those who were divorced, separated, widowed or never married); and (7) the presence of depression, as recorded by the Yesavage scale in its shortened version, which has 15 yes/no questions. ${ }^{17}$ Finally, treatments at discharge were also recorded.

\section{Mortality data}

After hospital discharge the patients were monitored by their usual doctors, receiving no intervention or follow-up provided by the investigators. Date and cause of death, whenever available, were collected up to 3 years after discharge. The search was carried out by telephoning the patient or family, and/or checking hospital records and the Mortality Register of Catalonia. ${ }^{18}$ Subjects who could not be located at follow-up and who were not clearly identified as dead were considered as censored after the time of last survival status assessment.

\section{Statistical analysis}

Qualitative variables are expressed in percentages, and quantitative variables are summarised as mean $\pm \mathrm{SD}$, if normality can be assumed, or as median and IOR (25th-75th percentile) to describe time values. The bivariate and multivariate relationship between survival time and covariates was determined with Cox proportional hazards regression models and graphically displayed with Kaplan-Meier curves. For all survival analysis, mortality was considered the dependent variable, and survival time was defined as the interval between hospital discharge and the date of death, or censored at the date of final follow-up for survivors. CIs were calculated for the HR of significant variables. Results were considered statistically significant at $\mathrm{p}<0.05$.

\section{RESULTS}

Overall, 379 patients were screened during the two periods, and 329 were included. Six patients $(4 \%)$ in the first cohort and seven $(3.7 \%)$ in the second were lost to follow-up (figure 1). Follow-up was available for 316 subjects (296 men and 20 women); of these, 135 participants belong to the 1996-7 cohort and 181 to the 2003-4 cohort.

Mean age of the entire population studied was 72.1 years (SD 9.6). A total of 134 patients (42.4\%) were dead 3 years after discharge. Median follow-up was 439 days for deceased patients (IOR 25-75\%: 145-775) and 998 days (IOR 25-75\%: 921-1088) for surviving patients. Although our study design did not use any matching criteria whatsoever, the two cohorts were comparable in their distribution by age, gender, co-morbidity, functional status and number of hospitalisations or emergency consultation for COPD exacerbation in the previous year (all p>0.05). However the 2003-4 cohort had a lower percentage of non-smoking patients $(p=0.02)$ and higher BMI $(p=0.006)$ (table 1). Mean length of stay was only reduced from 13.5 to 10 days $(p<0.001)$.
Figure 1 Flowchart (CONSORT) of study participants. *Unable to perform spirometry or do not fulfil minimum spirometric requirements.

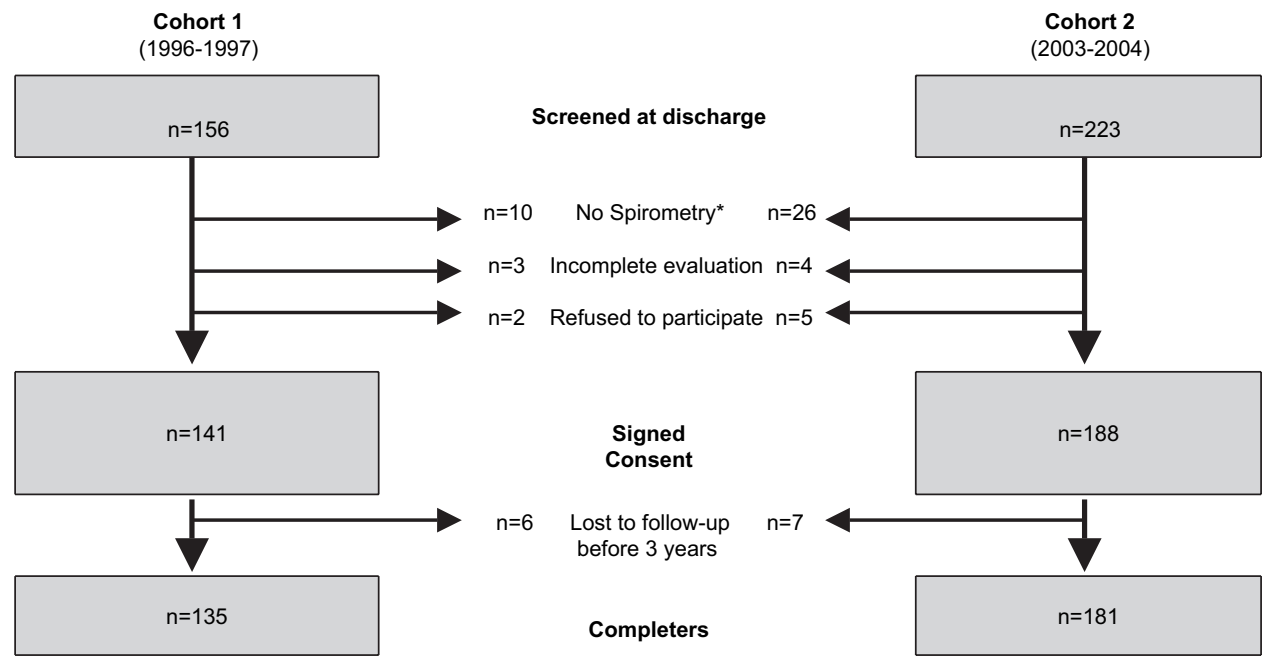


Table 1 Demographic and clinical variables by cohort

\begin{tabular}{|c|c|c|c|}
\hline & $1996-7$ & $2003-4$ & p Value \\
\hline $\mathrm{Age} \pm \mathrm{SD}$ & $72.3 \pm 9.2$ & $72.0 \pm 9.8$ & 0.8 \\
\hline Men $(\%)$ & $124(92 \%)$ & $172(95 \%)$ & 0.5 \\
\hline Smoking (\%) & & & 0.02 \\
\hline Current & $23(17 \%)$ & $41(23 \%)$ & \\
\hline Ex-smoker & $96(73 \%)$ & $132(75 \%)$ & \\
\hline Never-smoker & $14(10 \%)$ & $3(2 \%)$ & \\
\hline Married status (\%) & $102(76 \%)$ & $\begin{array}{l}120 \\
(75.5 \%)\end{array}$ & 1 \\
\hline Residential status (\%) & & & 0.6 \\
\hline Living alone & $\begin{array}{l}14 \\
(10.4 \%)\end{array}$ & $\begin{array}{l}19 \\
(12.0 \%)\end{array}$ & \\
\hline Living with family & $\begin{array}{l}118 \\
(88.1 \%)\end{array}$ & $\begin{array}{l}135 \\
(84.9 \%)\end{array}$ & \\
\hline Institutionalised & $2(1.5 \%)$ & $5(3.1 \%)$ & \\
\hline $\mathrm{BMI} \pm \mathrm{SD}$ & $26.3 \pm 4.9$ & $27.9 \pm 5.0$ & 0.006 \\
\hline Charlson index $\pm S D$ & $2.2 \pm 1.1$ & $2.1 \pm 1.34$ & 0.8 \\
\hline Yesavage index $\pm S D$ & $4.7 \pm 3.7$ & $5.1 \pm 3.6$ & 0.3 \\
\hline Functional status (Katz) $\pm S D$ & $5.4 \pm 1.2$ & $5.5 \pm 1.2$ & 0.5 \\
\hline \multicolumn{4}{|l|}{ COPD in the previous 12 months } \\
\hline No. of hospitalisations* & $1(0-2)$ & $1(0-2)$ & 0.2 \\
\hline ER visits* & $0(0-1)$ & $0(0-1)$ & 0.8 \\
\hline Days of stay $\pm S D$ & $13.5 \pm 9.6$ & $10 \pm 5.6$ & 0.0001 \\
\hline $\begin{array}{l}\text { COPD hospitalisations in the next } \\
12 \text { months* }^{*}\end{array}$ & $10-2$ & $1 \quad 0-2$ & 0.9 \\
\hline
\end{tabular}

*Median (IQR; 25-75\%).

$\mathrm{BMI}$, body mass index; COPD, chronic obstructive pulmonary disease; ER, Emergency room.

Regarding respiratory function, again the two cohorts were similar in most variables with non-significant differences, although the second cohort had on average more severe dyspnoea as measured by the mMRC scale $(p=0.03)$ and lower $\mathrm{PaO}_{2}$ at discharge $(p=0.009)$, with a higher $\mathrm{FEV}_{1}$ expressed as percentage of predicted (45.1\% vs $41.4 \%)$. However, as mentioned above, spirometry in the 2003-4 cohort was performed 1 month after discharge while for the 1996-7 cohort it was performed immediately before discharge (table 2). Only three patients in the 2003-4 cohort died between discharge and the scheduled outpatient follow-up visit 1 month later. They were still included, and previous lung function data were used. Interestingly, no differences were observed in the number or distribution of specific co-morbidities by cohort (table 3). At discharge the patients of the second cohort received more frequent treatment with long-acting $\beta_{2}$ agonists, tiotropium, angiotensin II receptor antagonists, statins and antiplatelet drugs (table 4).

The observed 3-year survival was $52.6 \%$ in the 1996-7 cohort and $61.3 \%$ in the $2003-4$ cohort; these differences were statis-

Table 2 Respiratory-related variables, by cohort

\begin{tabular}{lccl}
\hline & $\mathbf{1 9 9 6 - 7}$ & $\mathbf{2 0 0 3 - 4}$ & p Value \\
\hline $\mathrm{FEV}_{1} \mathrm{ml} \pm \mathrm{SD}$ & $989 \pm 376$ & $1054 \pm 375$ & 0.14 \\
$\mathrm{FEV}_{1} \%$ predicted $\pm \mathrm{SD}$ & $41.4 \pm 13.0$ & $45.1 \pm 14.4$ & 0.02 \\
$\mathrm{PaO}_{2}$ on admission $\pm \mathrm{SD}$ & $59.9 \pm 17.8$ & $62.7 \pm 20.4$ & 0.2 \\
$\mathrm{Pac0}_{2}$ on admission $\pm \mathrm{SD}$ & $44.8 \pm 12.6$ & $42.3 \pm 13.9$ & 0.2 \\
$\mathrm{PaO}_{2}$ at discharge $\pm \mathrm{SD}$ & $70 \pm 15$ & $63 \pm 10$ & 0.009 \\
$\mathrm{Pac0}_{2}$ at discharge & $41 \pm 8$ & $42 \pm 9$ & 0.2 \\
Dyspnoea by mMRC $\pm \mathrm{SD}$ & $2.4 \pm 1.3$ & $2.8 \pm 1.2$ & 0.03 \\
Cor pulmonale (\%) & $44(32.6 \%)$ & $60(33.5 \%)$ & 0.5 \\
Chronic oxygen therapy (\%) & $23(17.4 \%)$ & $32(17.9 \%)$ & 0.5
\end{tabular}

As described in the Methods section, spirometry was conducted at discharge in 1996-7, and at baseline in 2003-4.

$\mathrm{FEV}_{1}$, forced expiratory volume in $1 \mathrm{~s}$; mMRC, modified Medical Research Council scale.
Table 3 Distribution of selected co-morbidities, by cohort

\begin{tabular}{lccl}
\hline & $\begin{array}{l}\mathbf{1 9 9 6 - 7} \\
\mathbf{n}(\%)\end{array}$ & $\begin{array}{l}\mathbf{2 0 0 3 - 4} \\
\mathbf{n}(\%)\end{array}$ & p Value \\
\hline Ischaemic heart disease & $20(15)$ & $33(18)$ & 0.4 \\
Heart failure & $43(32)$ & $46(26)$ & 0.3 \\
Stroke & $11(8.3)$ & $9(5.1)$ & 0.4 \\
Diabetes mellitus & $18(13.5)$ & $29(16.4)$ & 0.5 \\
Kidney failure & $6(4.5)$ & $8(4.5)$ & 1 \\
Cancer & $6(4.5)$ & $15(8.5)$ & 0.1 \\
Liver cirrhosis & $4(3)$ & $9(5)$ & 0.3 \\
Charlson index \pm SD & $2.22 \pm 1.06$ & $2.19 \pm 1.34$ & 0.84 \\
\hline
\end{tabular}

tically significant (log rank $\mathrm{p}=0.017$, HR $0.811 .52,95 \%$ CI 0.68 to 0.96 ) (figure 2). Mortality causes by cohort are detailed in table 5 .

When analysing the association of mortality in patients with COPD and specific co-morbidities between the two cohorts, mortality had decreased in patients with concomitant heart failure $(p=0.002)$ or cancer $(p=0.003)$. These differences by cohort were sustained even after adjustment, in a multivariate model including heart failure or cancer, and both retained independent statistical significance (cohort $(p=0.04, \mathrm{HR} 1.5,95 \% \mathrm{CI}$ 1.07 to 2.1 ), heart failure ( $p=0.002$; HR $1.76,95 \%$ CI 1.23 to $2.53)$ ) and (cohort ( $p=0.008$, HR 1.6, 95\% CI:1.13 to 2.29$)$ and malignancy ( $p=0.01$, HR $2.47,95 \%$ CI 1.43 to 4.25$)$ ).

Overall, mortality was lower in the 2003-4 cohort than in the 1996-7 cohort (figure 3), even after adjusting for gender, age, BMI, co-morbidities, lung function and mMRC, $(p=0.01$, HR 0.66 (95\% CI 0.45 to 0.97$)$ ) (online supplement 1 ).

\section{DISCUSSION}

Our study concludes that survival in patients after hospital discharge with a COPD exacerbation has significantly improved in recent years, and that this improvement is probably due, at least in part, to a better management of COPD and its associated co-morbidities.

COPD is significantly associated with co-morbidities, an association that is even more common in hospitalised patients. ${ }^{19}$ In a previous study conducted by our group, patients with a Charlson index of $\geq 3$ were almost twice as likely to die during follow-up than those with lower scores ( $p<0.005$, HR 2.2, 95\% CI 1.26 to 3.84). ${ }^{11}$ In this study heart failure was the most common chronic disease found, and it was also associated with a lower survival rate. Although the current study shows no difference in the distribution of co-morbidities by cohort, it may be noted that the mortality of patients with COPD and heart failure or cancer is lower in the more recent group of patients. This finding is not surprising since the overall prognosis has

Table 4 Treatment at discharge, by cohort

\begin{tabular}{lccl}
\hline & $\mathbf{1 9 9 6 - 7}$ & $\mathbf{2 0 0 3 - 4}$ & p Value \\
& $\%$ & $\%$ & \\
\hline Short-acting $\beta_{2}$ agonists & 97.6 & 78.5 & 0.0001 \\
Long-acting $\beta_{2}$ agonists & 1.2 & 77.9 & 0.0001 \\
Ipratropium bromide & 89 & 58.1 & 0.0001 \\
Tiotropium & 0 & 33.1 & 0.0001 \\
Inhaled corticosteroids & 87.4 & 84.9 & 0.3 \\
Chronic systemic corticosteroids & 2.4 & 2.3 & 0.6 \\
Statins & 1.6 & 16.9 & 0.001 \\
ACE inhibitors & 27.6 & 27.3 & 0.5 \\
Angiotensin II receptor antagonists & 0 & 7.6 & 0.001 \\
$\beta$-Blockers & 1.6 & 5.8 & 0.057 \\
Antiplatelet drugs & 16.5 & 30.2 & 0.004 \\
\hline
\end{tabular}




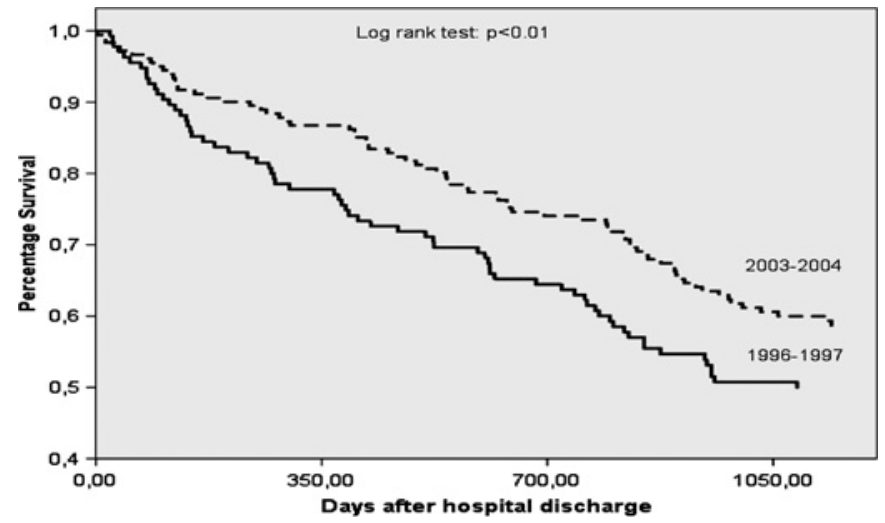

Figure 2 Kaplan-Meier survival curves of participants, by cohort. Log rank $p$ value $<0.01$.

improved for the most common malignancies. ${ }^{20} 21$ Similarly, mortality in patients with heart failure has diminished, probably linked to the use of ACE inhibitors, $\beta$-blockers, angiotensin receptor inhibitors and statins, as presented elsewhere. ${ }^{22}$ Of interest, several of these drugs have been associated with improved survival in patients with COPD, suggesting a possible direct benefit due to their anti-inflammatory effect. ${ }^{23} 24$ In our study, patients of the second cohort were more likely to receive treatment with statins, angiotensin II receptor antagonists or antiplatelet drugs for their co-morbodities. It is reasonable to hope that a more comprehensive approach to COPD together with its co-morbidities may modify the natural course of the disease. . $^{25}$

Until recently COPD was considered an irreversible disease. Existing treatments were considered symptomatic and, apart from oxygen therapy for patients with chronic respiratory failure and smoking cessation, there were no interventions that changed the natural history of the disease or increased survival. This pessimistic view was reflected in the old therapeutic guidelines for the management of COPD, which only recently have changed, identifying a reduction of mortality as a goal and priority. ${ }^{4} 1314$

New clinical trials performed in outpatients already hinted at a decrease in mortality of patients with COPD in recent years. For example, the TORCH mortality trial used data derived from the ISOLDE trial, ${ }^{26}$ conducted 10 years earlier, to calculate its sample size, expecting a 3 -year mortality of $17 \%$ in the placebo group, a lethality that was higher than that finally observed. ${ }^{7}$ The TORCH trial as well as INSPIRE, OPTIMAL and UPLIFT $^{7-10}$ were initiated to assess the usefulness of different respiratory drugs: long-acting $\beta_{2}$ agonists, inhaled corticosteroids and tiotropium. They obtained substantial reductions in exacerbations and hospitalisations, and improvements in quality of life; all these variables are directly associated with mortality. ${ }^{11} 2728$ However, except for INSPIRE, which showed an unexpectedly significant decrease in mortality in the group randomised to combined salmeterol-fluticasone versus the group randomised to

Table 5 Mortality causes, by cohort

\begin{tabular}{lcc}
\hline & $\begin{array}{l}\mathbf{1 9 9 6 - 7} \\
\mathbf{n}(\%)\end{array}$ & $\begin{array}{l}\mathbf{2 0 0 3 - 4} \\
\mathbf{n}(\%)\end{array}$ \\
\hline Respiratory disease & $32(50)$ & $31(44)$ \\
Cardiovascular disease & $12(19)$ & $10(14)$ \\
Cancer & $4(6)$ & $9(13)$ \\
Other & $3(5)$ & $4(6)$ \\
Unknown & $13(20)$ & $16(23)$ \\
\hline
\end{tabular}

tiotropium, all other trials to date have been unable to find a statistically significant improvement in survival. ${ }^{9}$ Particularly in TORCH, the only trial designed to evaluate a reduction in mortality, the primary objective of mortality from all causes was $12.6 \%$ in the group treated with combined salmeterolfluticasone versus $15.2 \%$ in the placebo group $(p=0.052){ }^{7}$ Similarly, in the UPLIFT study, the mortality in the tiotropium group was significantly reduced at 4 years $(14.4 \%$ vs $16.3 \%$; HR 0.87 ; $95 \%$ CI 0.76 to 0.99 ), although mortality at 4 years plus 30 days did not reach statistical significance (HR 0.89; 95\% CI 0.79 to 1.02). ${ }^{8} 29$

Any differences in mortality should be more easily observed in patients discharged after a hospitalisation, given their worsened prognosis. As mentioned above, patients with COPD have benefited in recent years from the availability of new drugs, more powerful and effective than older respiratory drugs. Again, patients from the second cohort were more likely to receive treatment with long-acting $\beta_{2}$ agonists and tiotropium, while the percentage of patients treated with inhaled corticoids was similar.

Some advantages and limitations of our study deserve discussion. Advantages include being conducted in the same hospital and by the same researchers, and the fact that clinically and demographically the two cohorts are homogeneous and comparable without matching by design. As mentioned above, study design is observational, by comparing two prospective cohorts. Comparisons of historical cohorts like ours are frequently used in other medical disciplines, but to date they have been scarcely used in respiratory research. ${ }^{30-32}$ The intrinsic strengths and limitations of this specific study design are discussed elsewhere, but we believe it is a major strength of our study that, even without any artificial matching by design,

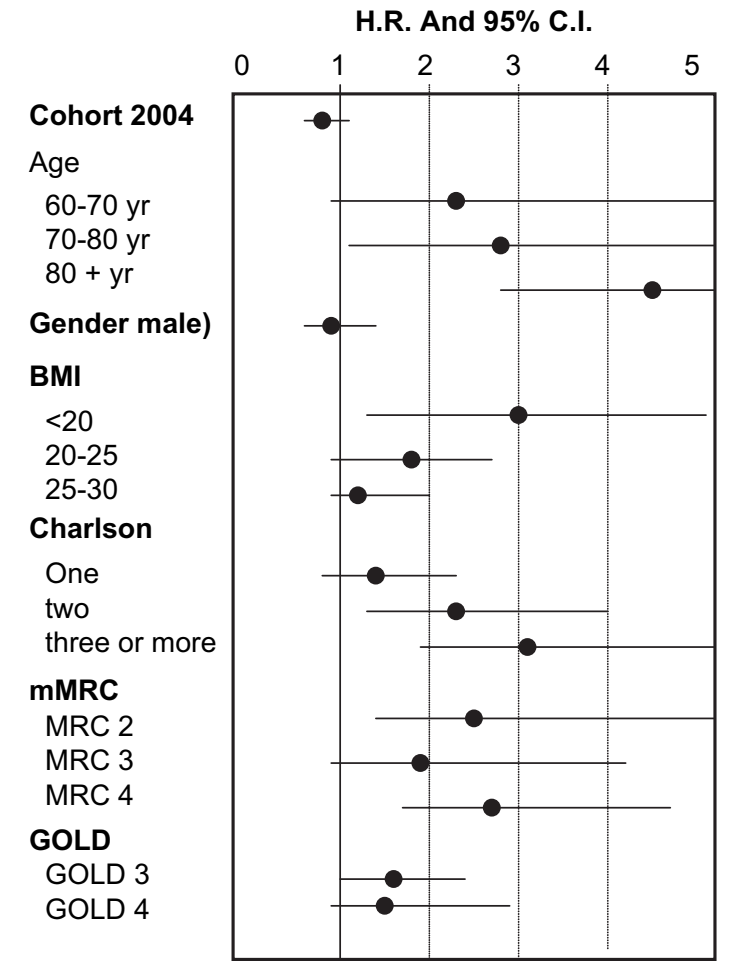

Figure 3 Multivariate model (Cox regression) of risk of death by covariates. Reference values are: cohort 1996, age 50-60 years, female, BMI (body mass index) $>30 \mathrm{~kg} / \mathrm{m}^{2}$, no co-morbidities, dyspnoea MRC 1 (Medical Research Council score) and GOLD (Global Initiative for Chronic Obstructive Lung Disease) 2 severity. 
the baseline characteristics of our two cohorts obtained 7 years apart are absolutely comparable (virtually identical) at discharge from hospital. At any rate, all results are adjusted at the individual level in the reported multivariate analyses. With current knowledge, it might be considered unethical to randomise patients to no treatment, either respiratory or non-respiratory, and by using recently discharged instead of stable COPD as in published clinical trials, the efficacy of these treatments appears maximised. Concerning the limitations, we should underline again that the spirometric data are not fully comparable, being obtained on the last day of admission for patients in the 1996-7 cohort and a month later for the 2003-4 cohort. This was done in the first cohort to minimise data loss during hospitalisation, and we reported no relationship between mortality and $\mathrm{FEV}_{1}{ }^{11}$ so procedures were changed for the 2003-4 cohort. Additionally, later research indicated that outcomes after a COPD exacerbation take weeks to return to baseline, or often never return to previous levels, so spirometry 1 month after discharge became our only protocol change. ${ }^{33}$ Moreover, the 6-minute walking test was not conducted in the first cohort and we are unable to show changes in the BODE index. A final limitation is the low number of women in our study, related to local smoking history exposure in our source population, although the frequency of women hospitalised with COPD we obtained is similar to that found in other studies in the same geographical area. ${ }^{34}$

In summary, our study identifies a significant mortality reduction after hospital discharge in patients with COPD nowadays, due in part to a better prognosis of heart failure and cancer, but also probably related to an improvement in our understanding and treatment of the disease. Our findings, if confirmed by others, should contribute to the abandonment of the unjustified nihilism that has accompanied COPD until recent times. ${ }^{35}$

Acknowledgements We thank Anna Puigdefabregas (Servei d'Informació i Estudis) for her assistance in searching for mortality data of some patients, and Tom Yohannan for his editorial assistance.

Funding This study was supported by a research grant from the Fundacio per la Recerca de Mutua de Terrassa (MI03/07).

\section{Competing interests None.}

Ethics approval This study was conducted with the approval of the University Hospital Mutua de Terrassa Research and Ethics Committee, and all subjects gave their written informed consent.

All co-authors accept responsibility for the conduct of this study and for the analysis and interpretation of the data. All co-authors helped write this manuscript and agree with the decisions made.

Provenance and peer review Not commissioned; externally peer reviewed.

\section{REFERENCES}

1. Mannino DM, Buist AS. Global burden of COPD: risk factors, prevalence, and future trends. Lancet 2007;370:765-73.

2. Mathers CD, Loncar D. Projections of global mortality and burden of disease from 2002 to 2030. PLoS Med 2006;3:e442.

3. Buist AS, McBurnie MA, Vollmer WM, et al. International variation in the prevalence of COPD (the BOLD Study): a population-based prevalence study. Lancet 2007:370:741-50.

4. Global Initiative for Chronic Obstructive Lung Disease (GOLD). Global strategy for the diagnosis, management and prevention of COPD. 2008. http://www. goldcopd.org.

5. Zvezdin B, Milutinov S, Kojicic M, et al. A postmortem analysis of major causes of early death in patients hospitalized with COPD exacerbation. Chest 2009:136:376-80.

6. Sin DD, Man SF. Pharmacotherapy for mortality reduction in chronic obstructive pulmonary disease. Proc Am Thorac Soc 2006;3:624-9.
7. Calverley PM, Anderson JA, Celli B, et al. Salmeterol and fluticasone propionate and survival in chronic obstructive pulmonary disease. N Engl J Med 2007;356:775-89.

8. Tashkin DP, Celli B, Senn S, et al. A 4-year trial of tiotropium in chronic obstructive pulmonary disease. N Engl J Med 2008:359:1543-54.

9. Wedzicha JA, Calverley PM, Seemungal TA, et al. The prevention of chronic obstructive pulmonary disease exacerbations by salmeterol/fluticasone propionate or tiotropium bromide. Am J Respir Crit Care Med 2008;177:19-26.

10. Aaron SD, Vandemheen KL, Fergusson D, et al. Tiotropium in combination with placebo, salmeterol, or fluticasone-salmeterol for treatment of chronic obstructive pulmonary disease: a randomized trial. Ann Intern Med 2007;146:545-55.

11. Almagro $\mathbf{P}$, Calbo $E$, Ochoa de Echagüen $A$, et al. Mortality after hospitalization for COPD. Chest 2002:121:1441-8.

12. Groenewegen $\mathbf{K H}$, Schols AM, Wouters EF. Mortality and mortality-related factors after hospitalization for acute exacerbation of COPD. Chest 2003:124:459-67.

13. Celli BR, MacNee W. American Thoracic Society/European Respiratory Society Task Force. Standards for the diagnosis and treatment of patients with COPD: a summary of the ATS/ERS position paper. Eur Respir J 2004;23:932-46.

14. Peces-Barba G, Barberà JA, Agustí A, et al. Diagnosis and management of chronic obstructive pulmonary disease: joint guidelines of the Spanish Society of Pulmonology and Thoracic Surgery (SEPAR) and the Latin American Thoracic Society (ALAT). Arch Bronconeumol 2008;44:271-81.

15. Charlson ME, Pompei P, Ales KL, et al. A new method of classifying prognostic comorbidity in longitudinal studies: development and validation. J Chronic Dis 1987:40:373-83

16. Katz S, Ford AB, Moskowitz RW, et al. Studies of illness in the aged. The index of ADL: a standardized measure of biological and psychosocial function. JAMA 1963; 185:914-9

17. Seikh JI, Yesavage JA. Geriatric depression scale (GDS): recent evidence and development of a shorter version. Clin Gerontol 1986;6:165-73.

18. Mortality Register of Catalonia. Serveis d'Informació i estudis. Direcció general de recursos sanitaris. Departament de salut (elaboración propia).

19. Antonelli Incalzi R, Fuso L, De Rosa M, et al. Co-morbidity contributes to predic mortality of patients with chronic obstructive pulmonary disease. Eur Respir $J$ 1997:10:2794-800.

20. Verdecchia A, Guzzinatis S, Francisci S, et al. Survival trends in European cancer patients diagnosed from 1988 to 1999. Eur J Cancer 2009;45:1042-66.

21. Brrino F, De Angelis R, Sant M, et al. Survival for eight major cancers and all cancers combined for European adults diagnosed in 1995-99: results of the EUROCARE-4 study. Lancet Oncol 2007:8:773-883.

22. Shafazand $\mathbf{M}$, Schaufelberger $\mathbf{M}$, Lappas $\mathbf{G}$, et al. Survival trends in men and women with heart failure of ischaemic and non-ischaemic origin: data for the period 1987-2003 from the Swedish hospital discharge registry. Eur Heart J 2009;30:671-8.

23. Janda S, Park K, Fitzgerald JM, et al. Statins in COPD: a systematic review. Chest 2009:136:734-43.

24. Mancini GB, Etminan M, Zhang B, et al. Reduction of morbidity and mortality by statins, angiotensin-converting enzyme inhibitors, and angiotensin receptor blockers in patients with chronic obstructive pulmonary disease. J Am Coll Cardiol 2006; 47:2554-60.

25. Luppi F, Franco F, Beghe B, et al. Treatment of chronic obstructive pulmonary disease and its comorbidities. Proc Am Thorac Soc 2008;5:848-56.

26. Burge PS, Calverley PM, Jones PW, et al. Randomised, double blind, placebo controlled study of fluticasone propionate in patients with moderate to severe chronic obstructive pulmonary disease: the ISOLDE trial. BMJ 2000;320:1297-303.

27. Soler-Cataluña JJ, Martínez-García MA, Román Sánchez $P$, et al. Severe acute exacerbations and mortality in patients with chronic obstructive pulmonary disease. Thorax 2005;60:925-31.

28. Domingo-Salvany A, Lamarca $\mathrm{R}$, et al. Health-related quality of life and mortality in male patients with chronic obstructive pulmonary disease. Am J Respir Crit Care Med 2000;166:680-5

29. Celli B, Decramer M, Kesten $S$, et al. Mortality in the 4 year trial of tiotropium (UPLIFT) in patients with COPD. Am J Respir Crit Care Med 2009;180:948-55.

30. Rundle AG, Vineis P, Ahsan H. Design options for molecular epidemiology research within cohort studies. Cancer Epidemiol Biomarkers Prev 2005;14:1899-907.

31. Sitbon 0, McLaughlin VV, Badesch DB, et al. Survival in patients with class III idiopathic pulmonary arterial hypertension treated with first line oral bosentan compared with an historical cohort of patients started on intravenous epoprostenol. Thorax 2005;60:1025-30.

32. McWilliams JM, Meara E, Zaslavsky AM, et al. Differences in control of cardiovascular disease and diabetes by race, ethnicity, and education: U.S. trends from 1999 to 2006 and effects of medicare coverage. Ann Intern Med 2009;21;150-15.

33. Seemungal TA, Donaldson GC, Bhowmik A, et al. Time course and recovery of exacerbations in patients with chronic obstructive pulmonary disease. Am J Respir Crit Care Med 2000;161:1608-13.

34. Garcia-Aymerich J, Barreiro E, Farrero E, et al. Patients hospitalized for COPD have a high prevalence of modifiable risk factors for exacerbation (EFRAM study) Eur Respir J 2000:16:1037-42.

35. Celli BR. Update on the management of COPD. Chest 2008;133:14512-62. 